
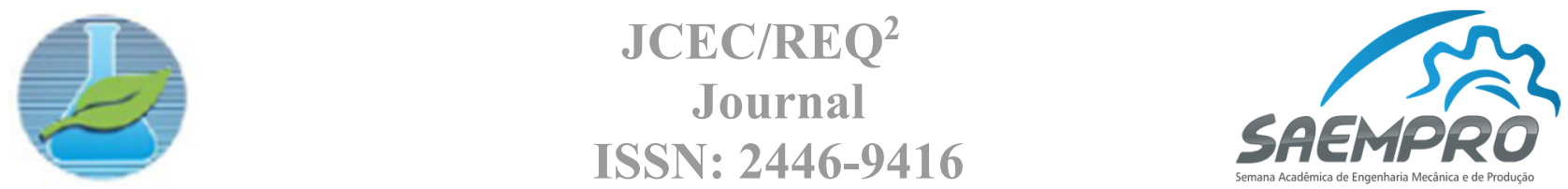

\footnotetext{
"EU, A INDÚSTRIA E O MUNDO"

08 a 11 de novembro de 2016 no campus Viçosa da UFV

Departamento de Engenharia de Produção e Mecânica - DEP

Universidade Federal de Viçosa - UFV
}

\title{
PROJETO DE UM SISTEMA DE TRANSMISSÃO PARA VEÍCULO DO TIPO FÓRMULA SAE STUDENT
}

\author{
José Geraldo Alves Coutinho Filho, Lucas Benini \\ Universidade Federal de Viçosa - Departamento de Engenharia de Produção e Mecânica \\ Avenida Peter Henry Rolfs, s/n - Campus Universitário - 36570-900 - Viçosa - MG \\ jose.coutinho@ufv.br, lucas.benini@ufv.br
}

\section{INTRODUÇÃ̃O}

Este trabalho apresenta os resultados preliminares do projeto de um sistema de rodas dentadas e correntes de rolos para o sistema de transmissão de um veículo tipo Fórmula Student. Este veículo deve estar de acordo com as normas da competição Fórmula SAE estipuladas pela Sociedade dos Engenheiros Automotivos. Esta competição visa promover a prática de engenharia entre estudantes na construção de veículo protótipo tipo fórmula, monoposto e openwheels, simulando um sistema empresarial e industrial voltado para o meio automobilístico ainda durante a graduação.

\section{O PROJETO}

A competição Fórmula SAE apresenta um regulamento o qual todas as equipes participantes devem nortear seus projetos; há restrições estabelecidas por normas de segurança e limitações impostas para a simplificação do projeto. Em questão, tem-se o projeto do sistema de transmissão do veículo que será completamente desenvolvido de acordo com os requisitos do regulamento.

A princípio, todas as equipes podem selecionar o tipo de transmissão para uso no projeto. Entretanto, é importante ressaltar que a escolha de um sistema simples influencia diretamente no custo do final do produto e em sua construção. A seleção deste conjunto, dá-se a partir do tipo de motor que é comumente utilizado: de acordo com o regulamento o sistema de transmissão não pode ultrapassar $600 \mathrm{cc}$ de volume máximo admitido no cilindro do pistão. Portanto, motores de motocicleta figuram-se como o modelo mais interessante de máquina. No caso, utiliza-se o motor do veículo Honda CB 600F. Devido a configuração apresentada para acoplamento da roda motora conectada ao motor para a transmissão de torque/movimento, restringe-se o sistema de transmissão a ser selecionado em três tipos: rodas dentadas e correntes de rolos, engrenagens e corrente dentada, e engrenagens. Este último, por razões de desgaste por fadiga torna-se completamente inviável durante a competição. De acordo com Birrento (2008) a corrente de rolos é a melhor opção para o caso do Fórmula SAE, e por este motivo selecionou-se este tipo de transmissão para o projeto do veículo.

\section{METODOLOGIA}

O estudo do projeto foi dividido em três etapas: estudo teórico, que utiliza os princípios de elementos de máquinas, resistência dos materiais e ciência dos materiais, baseado em Budynas e Nisbett (2011) e Birrento (2008); análise por elementos finitos no software Solidworks Simulation ${ }^{\circledR}$ suportado pela versão 2016; e análise e discussão dos resultados obtidos nas etapas anteriores.

\section{RESULTADOS}


Durante a realização da primeira etapa verificou-se que os principais fatores que influenciam no desempenho veículo são: material do sistema, número de dentes e norma das rodas dentadas, norma da corrente de rolos e distância entre centros da roda dentada (que devem estar devidamente alinhados paralelamente). Compilou-se então uma planilha de cálculos para facilitar a organização e análise dos dados - considerando os dados fornecidos pelo fabricante do motor e pelo fabricante de engrenagens JTS. Obteve-se alguns resultados significativos, sendo os mais importantes os referentes a força útil e centrífuga exercidas pela corrente de rolos, além da velocidade final e aceleração inicial das rodas dentadas.

A transmissão original da CB 600F obedece-se a relação de 2.8 e fornece uma força útil de $1591 \mathrm{~N}$ (diretamente ligada ao torque transmitido da roda dentada motora para a movida) e tem força centrífuga de $259 \mathrm{~N}$ (relacionada ao peso da corrente), além de aceleração baixa. Com a nova transmissão dimensionada para relação 3.0, esses dados passaram a ser $1705 \mathrm{~N}$ e $225 \mathrm{~N}$, além de haver uma significativa melhora na aceleração inicial. A corrente selecionada foi de 520 (Norma DIN 10B-1). Para a segunda etapa construiu-se o projeto deste sistema, como pode ser observado na Fig. 1:

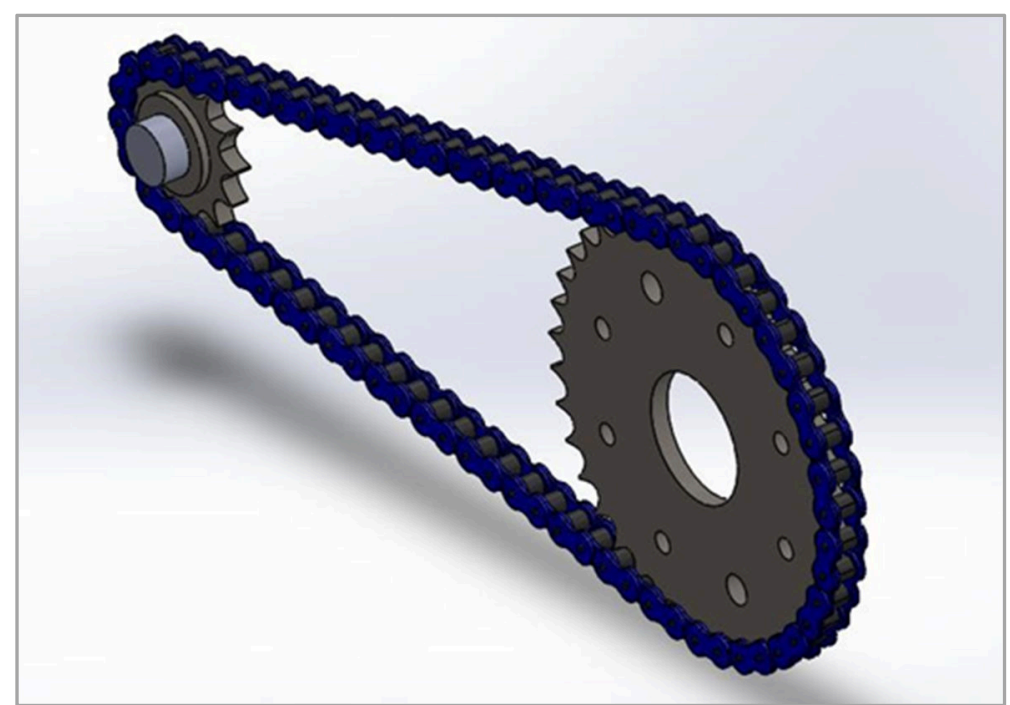

Figura 1 - Projeto do sistema de transmissão em sistema CAD.

Utilizando os esforços calculados utilizou-se o método de elementos finitos para análise estrutural dos componentes em tensão de Von-Mises considerando o material como o aço AISI 1020, apresentados nas Fig. 2 e 3.

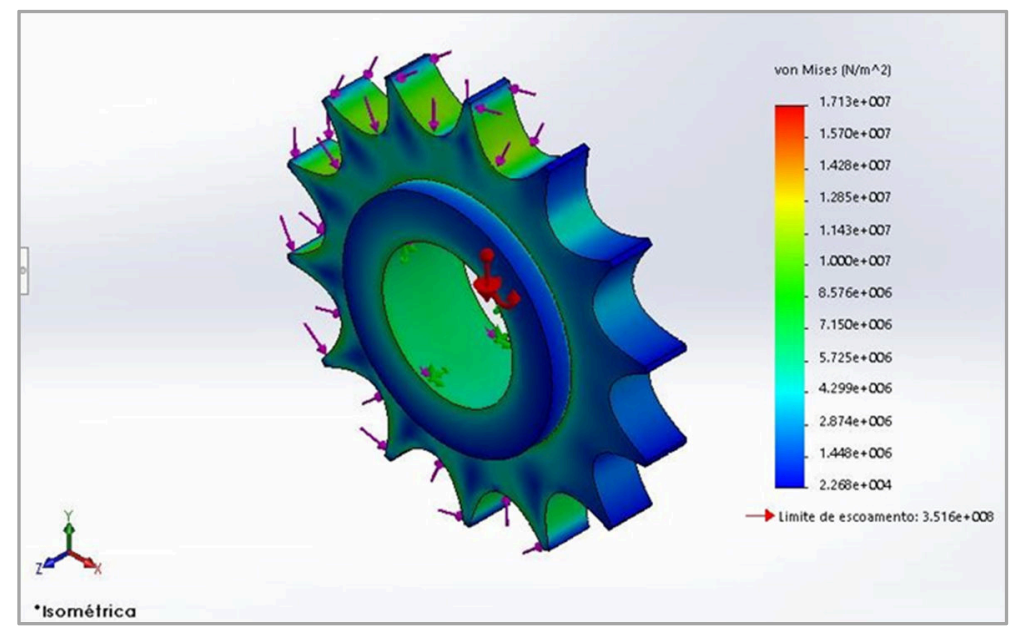

Figura 2 - Resultado da análise estrutural da roda dentada motora. 


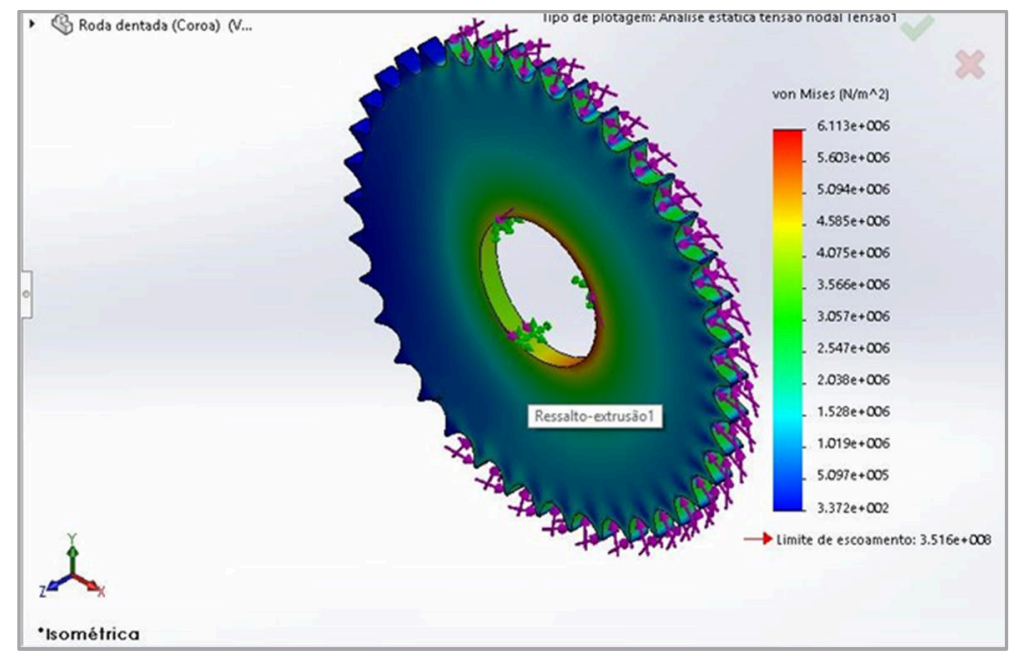

Figura 3 - Resultado da análise estrutural e roda dentada movida.

As correntes não foram analisadas, pois o todos os fabricantes garantem que para motores de 600 cc todas suportam a carga máxima do mesmo na transmissão por rodas dentadas em aço AISI 1020. A análise dos resultados obtidos (terceira etapa do projeto) conclui-se que efetuar modificações no sistema original de transmissão do motor Honda CB600F possibilita melhorias no desempenho do veículo.

\section{CONSIDERAÇÕES FINAIS}

Através das modificações no sistema original de transmissão do motor selecionado verificouse uma melhora no desempenho do veículo, seja em questões da cinemática ou da dinâmica. Ademais, percebe-se que os novos valores de dimensão estão de acordo com as normas de segurança, visto que o limite de escoamento calculado é inferior ao limite de escoamento máximo suportado em todos os casos. Com isto, tem-se então o projeto conceitual dos principais componentes do sistema de transmissão para um veículo do tipo Fórmula SAE Student.

\section{AGRADECIMENTOS}

Aos estudantes e amigos Mateus Vidal, André Scalzer e Gabriela Toledo pela determinação e motivação para criação da equipe de estudos relacionados a Equipe Fórmula Majorados.

\section{REFERÊNCIAS}

BIRRENTO, R. J. P. "Projeto de um Sistema de Transmissão de um veículo de competição Fórmula Student". Dissertação (Mestrado) - Curso de Engenharia Mecânica, Departamento de Engenharia Mecânica e Industrial, Universidade Nova de Lisboa, Lisboa, 2008.

BUDYNAS, R. G.; NISBETT, J. K. "Elementos de Máquinas de Shigley: Projeto de Engenharia Mecânica”. 8. ed. Porto Alegre: Amgh Editora Ltda., 2011.

JTS. "Gear ratios for sprockets". Acesso em; 1 mar. 2016. Disponível em: $<$ www.jtsprockets.com/fileadmin/files/jtgearratio.pdf $>$ 